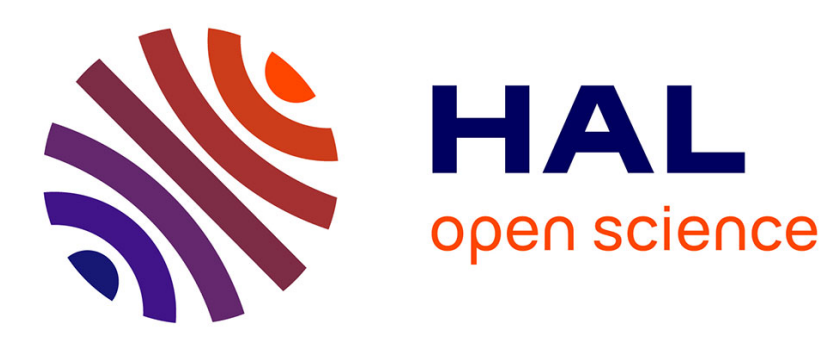

\title{
Evaluation of surgical methods for treatment of cubital tunnel syndrome - statistical perspectives
}

\author{
Ahmed Mohammed Morsy
}

\section{To cite this version:}

Ahmed Mohammed Morsy. Evaluation of surgical methods for treatment of cubital tunnel syndrome - statistical perspectives. Clinical Trials in Orthopedic Disorders, 2017, 2 (3), pp.121-122. 10.4103/2542-4157.213690 . hal-01580757

\section{HAL Id: hal-01580757 https://hal.science/hal-01580757}

Submitted on 2 Sep 2017

HAL is a multi-disciplinary open access archive for the deposit and dissemination of scientific research documents, whether they are published or not. The documents may come from teaching and research institutions in France or abroad, or from public or private research centers.
L'archive ouverte pluridisciplinaire HAL, est destinée au dépôt et à la diffusion de documents scientifiques de niveau recherche, publiés ou non, émanant des établissements d'enseignement et de recherche français ou étrangers, des laboratoires publics ou privés. 


\title{
Evaluation of surgical methods for treatment of cubital tunnel syndrome - statistical perspectives
}

\author{
Ahmed Mohammed Morsy* \\ Pediatric Oncology Department, South Egypt Cancer Institute, Assiut University, Assiut, Egypt \\ *Correspondence to: Ahmed Mohammed Morsy, ahmedmohammed7829@yahoo.com. \\ orcid: 0000-001-5617-8797 (Ahmed Mohammed Morsy)
}

\section{Abstract}

This commentary addresses strengths and weaknesses of the clinical trial study protocol designed by Liu et al., in particular with regard of the methodology, taking into consideration the commentary article "Assessing surgical methods for treatment of cubital tunnel syndrome - which is the best?" Our commentary emphasizes the importance of adjustment for known prognostic covariates, such as duration of symptoms and advanced age that have been negatively correlated with outcomes in previous studies. Subgroup analysis for the treatment groups of interest, namely moderate and severe cubital tunnel syndrome, which have previously shown conflicting differences in efficacy of surgical options is highly recommended. Intention-to-treat analysis is a preferable approach for the evaluation of primary outcome measures to lessen the bias. Use of well-validated composite outcome measure is strongly encouraged.

Key words: cubital tunnel syndrome; orthopedic surgery; research methodology; medical statistics

doi: $10.4103 / 2542-4157.213690$

How to cite this article: Morsy AM. Evaluation of surgical methods for treatment of cubital tunnel syndrome - statistical perspectives. Clin Trials Orthop Disord. 2017;2(3):121-122.

Although stringent methodological criteria have been sufficiently fulfilled in both of the study protocol \& the commentary article, ${ }^{1,2}$ besides that the study protocol has been designed to permit randomized allocation of participants, which is often considered the gold standard for a clinical trial; however, surgeons increasingly recognized the limitations of a randomized clinical trial, where there are inevitable number of variables that are not amenable for randomization such as, each patient had unique baseline findings, each surgeon had different skills, and each operation involved countless choices about anesthesia, premedication, surgical approach, instrumentation, and postoperative care, all of which challenged the notion that clinical trials are insistently required. ${ }^{3}$

As a critical appraisal for the clinical trial study protocol of Liu et al., ${ }^{1}$ potential areas of improvement of the protocol could enhance the study yield, mostly from the statistical analysis point of view still remains. These points summarized here needed to be addressed \& considered as follows.

In practice, simple randomization may not ensure balance in some important covariates. Stratification and minimization are not alternatives to covariate adjusted analysis. ${ }^{4}$ The difference between treatment groups in the outcome should be adjusted for baseline score, disease, and demographic covariates, and have to be considered, in particular for known prognostic covariates, such as the duration of symptoms and advanced age that have been negatively correlated with outcomes in previous studies. ${ }^{5,6}$ In addition, a well conducted observational study can be more valuable than randomized controlled trials with distorted randomization, as statistical adjustment for strong predictors of outcome and overall interpretations usually take bias in nonexperimental studies into consideration. ${ }^{7-9}$

A sub-group analysis ${ }^{10,11}$ to compare the difference between the treatments for the sub-groups of interest should be performed; namely, for moderate and severe cubital tunnel syndrome that have previously shown differences in efficacy of surgical options. ${ }^{12}$ To estimate differences in treatment effect within subgroups (a subgroup effect), ${ }^{13}$ the treatment interaction effect could be examined using multivariate analysis within an appropriate regression model. ${ }^{14}$

To calculate the study sample size ${ }^{15}$ based on the size of treatment effects, taking into account expected dropout during follow-up to have an appropriate estimate of the sample size needed to detect differential subgroup effects. ${ }^{16}$ Generally, the larger the effect size, ${ }^{17}$ the greater the difference between treatment groups in the outcome measure, and the lower the sample size that is required.

Intention-to-treat analysis ${ }^{18}$ would be the preferred approach for the evaluation of primary outcome measures, particularly to overcome bias that could result when the reasons for non- 
adherence to the protocol are related to prognosis. This implies that patients are always analyzed in the group to which they were initially randomized ${ }^{19}$ even if they drop out of the study.

Standardized clinical outcome metrics ${ }^{20}$ would be better to be used if possible, as no universally standardized metrics are present to assess clinically relevant improvement in function compared to baseline. Although various rating systems for improvement exist, these have not been universally adopted. ${ }^{21}$

A reliable and well-validated composite measure could be constructed using "Area under the Receiver Operating Characteristic" (ROC) curve. ${ }^{22}$ Composite measure ${ }^{23}$ in statistics and research design refer to combining multiple individual measures of various outcome parameters ${ }^{24}$ that are assumed to be associated with variation in diagnostic accuracy. ROC curve is an index of overall inherent validity of the test as well as used for comparing the sensitivity and specificity at particular cutoffs of interest. ${ }^{25}$ Composite measures could be developed \& validated to assess surgical performance or morbidity in hospitals. ${ }^{26,27}$

It would be better if an estimate of concordance between two outcome assessors (Inter-rater agreement ${ }^{28}$ was used to give a report about subjective clinical data dependent on (1) assessor judgment, (2) patient-reported; such as muscle strength, grip and pinch strength of the hand, and sensation.

\section{Author contributions}

AMM wrote the paper, read and approved the final version of the paper for publication.

Conflicts of interest

None declared.

Plagiarism check

Checked twice by iThenticate.

Peer review

Externally peer reviewed.

Open access statement

This is an open access article distributed under the terms of the Creative Commons Attribution-NonCommercial-ShareAlike 3.0 License, which allows others to remix, tweak, and build upon the work noncommercially, as long as the author is credited and the new creations are licensed under the identical terms.

\section{RefEREnCES}

1. Liu QQ, Li R. Cubital tunnel syndrome treated with ulnar nerve simple decompression, anterior intramuscular or subcutaneous transposition: a parallel randomized controlled clinical trial. Clin Trials Orthop Dis. 2016;1:15.

2. Burtt KE, Badash I, Wu B. Assessing surgical methods for treatment of cubital tunnel syndrome - which is the best? Clin Trials Orthop Disord. doi: 10.4103/2542-4157.213700.

3. Bothwell LE, Greene JA, Podolsky SH, Jones DS. Assessing the gold standard - lessons from the history of RCTs. N Engl J Med. 2016;374:2175-2181.

4. Kahan BC, Jairath V, Doré CJ, Morris TP. The risks and rewards of covariate adjustment in randomized trials: an assessment of 12 outcomes from 8 studies. Trials. 2014;15:139.

5. Gökay N, Bagatur AE. Subcutaneous anterior transposition of the ulnar nerve in cubital tunnel syndrome. Acta Orthop Traumatol Turc. 2011;46:243-249.
6. Huang W, Zhang PX, Peng Z, Xue F, Wang TB, Jiang BG. Anterior subcutaneous transposition of the ulnar nerve improves neurological function in patients with cubital tunnel syndrome. Neural Regen Res. 2015;10:1690-1695.

7. Egbewale BE. Statistical issues in randomised controlled trials: a narrative synthesis. Asian Pac J Trop Biomed. 2015;5:354-359.

8. Cotton P. Randomization is not the (only) answer: a plea for structured objective evaluation of endoscopic therapy. Endoscopy. 2000;32:402-405.

9. Torgerson DJ, Roberts C. Randomisation methods: concealment. BMJ. 1999;319:375-376.

10. Wang R, Ware JH. Detecting moderator effects using subgroup analyses. Prev Sci. 2013;14:111-120.

11. Wang R, Lagakos SW, Ware JH, Hunter DJ, Drazen JM. Statistics in medicine - reporting of subgroup analyses in clinical trials. $N$ Engl J Med. 2007;357:2189-2194.

12. Mowlavi A, Andrews K, Lille S, Verhulst S, Zook EG, Milner S. The management of cubital tunnel syndrome: a meta-analysis of clinical studies. Plast Reconstr Surg. 2000;106:327-334.

13. Dijkman B, Kooistra B, Bhandari M. How to work with a subgroup analysis. Can J Surg. 2009;52:515.

14. Fairchild AJ, MacKinnon DP. A general model for testing mediation and moderation effects. Prev Sci. 2009;10:87-99.

15. Sakpal T. Sample size estimation in clinical trial. Perspect Clin Res. 2010;1:67-69.

16. Brookes ST, Whitley E, Peters TJ, Mulheran PA, Egger M, Davey Smith G. Subgroup analyses in randomised controlled trials: quantifying the risks of false-positives and false-negatives. Health Technol Assess. 2001;5:1-56.

17. Coe R. It's the effect size, stupid: What effect size is and why it is important. 2002.

18. Gupta SK. Intention-to-treat concept: a review. Perspect Clin Res. 2011;2:109.

19. Fergusson D, Aaron SD, Guyatt G, Hébert P. Post-randomisation exclusions: the intention to treat principle and excluding patients from analysis. BMJ. 2002;325:652-654.

20. Porter ME, Larsson S, Lee TH. Standardizing patient outcomes measurement. $N$ Engl J Med. 2016;374:504-506.

21. Liu CH, Wu SQ, Ke XB, et al. Subcutaneous versus submuscular anterior transposition of the ulnar nerve for cubital tunnel syndrome: a systematic review and meta-analysis of randomized controlled trials and observational studies. Medicine. 2015;94:e1207.

22. Steyerberg EW, Vickers AJ, Cook NR, et al. Assessing the performance of prediction models: a framework for some traditional and novel measures. Epidemiology. 2010;21:128-138.

23. Shwartz M, Restuccia JD, Rosen AK. Composite measures of health care provider performance: a description of approaches. Milbank Q. 2015;93:788-825.

24. Velentgas P, Dreyer NA, Wu AW. Outcome definition and measurement. In: Velentgas P, Dreyer NA, Nourjah P, et al., eds. Developing a Protocol for Observational Comparative Effectiveness Research: A User's Guide. AHRQ Publication No.12(13)-EHC099. Rockville, MD: Agency for Healthcare Research and Quality; January 2013: Chapter 6, pp. 71-92.

25. Kumar R, Indrayan A. Receiver operating characteristic (ROC) curve for medical researchers. Indian Pediatr. 2011;48:277-287.

26. Staiger DO, Dimick JB, Baser O, Fan Z, Birkmeyer JD. Empirically derived composite measures of surgical performance. Med Care. 2009; 47:226-233.

27. Dimick JB, Staiger DO, Hall BL, Ko CY, Birkmeyer JD. Composite measures for profiling hospitals on surgical morbidity. Ann Surg. 2013;257:67-72.

28. Hallgren KA. Computing inter-rater reliability for observational data: an overview and tutorial. Tutor Quant Methods Psychol. 2012;8:23-34 